\title{
Elastic Rebound Research in Cold Bending Processing on Aluminum Alloy Plate
}

\author{
Libin Zhou ${ }^{1, a}$, Huanguo Chen ${ }^{2, b}$ \\ ${ }^{1}$ School of Mechanical and Power Engineering,Dalian Ocean University,Dalian,116023,China \\ ${ }^{2}$ Dalian Liaonan Shipyard, Dalian,116041, China. \\ aemail: zlb@dlou.edu.cn, bemail:zlbchg@163.com
}

Keywords: aluminum alloy plate; cold bending processing; elastic rebound; test

\begin{abstract}
Taking 5083 aluminum alloy plate in cold bending test for example, according to the different measuring results of the elastic rebound angle, the bending properties of 5083 aluminum alloy is studied.And the data statistics and analysis are finished,The experience curve of "the rebound angle with $\mathrm{R} / \mathrm{s}$ " is drawn. So not only it clearly provides the theory basis for the thermal deformation of the workpieces in cold bending,but also it gives the methord of expanding range of the cold working processing in order to decrease the heating deformation to some extent.
\end{abstract}

\section{Introduction}

A few years ago,the theory and the test about 5083 aluminum alloy plate are studied [1-2] .At present, the research on 5083 aluminum alloy is mainly concentrated in the aspects of the organizational performance, the corrosion resistance and the chemical composition.But the research on the bending properties of 5083 aluminum alloy is relatively less and less[3]. As we know that the thermal conductivity and linear expansion coefficient of the aluminum alloy are larger than that of the steel, also it has the lower melting point than that steel.Especially,the heating temperature is limited by the super heating temperature, and the change of the colour in heating is not obvious.So it is difficult to control the heating temperature, which brings great difficulties to the thermal processing, In this condition we have the necessary to try to expand the range of the cold working processing.

If the workpiece is subjected to bending in the mold, the elastic deformation will happen in the bending belt.So when the workpiece is taken out of the mold, the bending angle and the bending radius will both change.The general rule is that the bending tends to the shape as before.This phenomenon is called "elastic rebound". The minimum bending radius is one of the important technical parameters which have influence on the bending crack of the aluminum alloy plate [4] . When the minimum bending radius is larger than the radius of the arc ,not only the rebound angle is larger than it had before, but also the radius of the arc is changing greater. Thus how to predict the shape after the workpiece is bent and rebound, and how to amend the mold are both still difficult problems in actual processing [5] .

\section{The "elastic rebound" forming test in the cold bending processing about Aluminum plate}

In the test,we'd like to select three types of workpieces.Their specifications and bending angles in the test are shown as table 1.

Table 1 The specifications and angle in the test

\begin{tabular}{cccccccc}
\hline Numble of the workpieces & Specification & Numbers & \multicolumn{5}{c}{ The benging angle } \\
\cline { 3 - 7 } & & & 1 & 2 & 3 & 4 & 5 \\
\hline 1 & $1000 \times 1500 \times 4$ & 3 & & & $90^{\circ}$ & $120^{\circ}$ & $150^{\circ}$ \\
\hline 2 & $240 \times 500 \times 4$ & 9 & & & $90^{\circ}$ & $120^{\circ}$ & $150^{\circ}$ \\
\hline 3 & $50 \times 200 \times 4$ & 20 & $30^{\circ}$ & $60^{\circ}$ & $90^{\circ}$ & $120^{\circ}$ & $150^{\circ}$ \\
\hline
\end{tabular}

At first,we select the sample 1 to finish $90^{\circ}$ bending angle test.Accoring to the bending angle,we make the bending angle processing $(\mathrm{R} / \mathrm{S}=3)$. After the workpiece of the sample is bent and 
measured, we put the measurement results into Table 2.

Table2 The value of $90^{\circ}$ rebound

\begin{tabular}{lllllll}
\hline $\begin{array}{l}\text { value } \\
\text { Sample }\end{array}$ & Rebound & h1 & h2 & h3 & h4 & h5 \\
\hline 1 & 34.5 & 16 & 0 & 17.5 & 35 \\
\hline 2 & 34.5 & 15.5 & 0 & 17 & 34.5 \\
\hline 3 & 34 & 17 & 0 & 16.5 & 34 \\
\hline
\end{tabular}

After the first bending is finished, all the measuring points are measured for a total of 5 times every day.The measured results as a record are put into Table 2. According to the measured data, the elastic rebound value is calculated as:

$$
\Delta \alpha=\left(\Delta \alpha_{1}+\Delta \alpha_{2}+\Delta \alpha_{3}+\Delta \alpha_{4}+\Delta \alpha_{5}\right)=9.635^{\circ}
$$

The statistical analysis is performed through the measuring data .According to the changing trend of the data,the individual singular points are deleted, then the rest with regularity of the data is selected as the data of "the rebound angle curve".

In the second test, we select the sample 2 to finish $120^{\circ}$ bending angle test.Accoring to the test angle,we make the bending angle processing $(\mathrm{R} / \mathrm{S}=5)$. After the workpiece of the sample is bent and measured, we put the measurement results into Table 3.

Table 3 The value of $120^{\circ}$ rebound

\begin{tabular}{rlllll}
\hline $\begin{array}{l}\text { value } \\
\text { Sample }\end{array}$ & hebound & h2 & h3 & h4 & h5 \\
\hline 1 & 48.5 & 25 & 0 & 24.5 & 49 \\
\hline 2 & 49 & 24 & 0 & 25 & 49.5 \\
\hline 3 & 50 & 25 & 0 & 24 & 49.5 \\
\hline
\end{tabular}

After the first bending is finished, all the measuring points are measured for a total of at least 5 times every day.The measured results as a record are put into Table 3. According to the measured data, the elastic rebound value is calculated as:

$$
\Delta \alpha=\left(\Delta \alpha_{1}+\Delta \alpha_{2}+\Delta \alpha_{3}+\Delta \alpha_{4}+\Delta \alpha_{5}\right)=14.158^{\circ}
$$

The statistical analysis is performed through the measuring data .According to the changing trend of the data, the individual singular points are all deleted, then the regular datas are left as the basis of "the rebound angle curve".

In the third test, we select the sample 3 to finish $150^{\circ}$ bending angle test.Accoring to the test angle,we make the bending angle processing. After the workpiece of the sample is bent and measured, we put the measurement results into Table 4.

Table 4 The value of $150^{\circ}$ rebound

\begin{tabular}{rlllll}
\hline $\begin{array}{l}\text { value } \\
\text { Sample }\end{array}$ & h1 & h2 & h3 & h4 & h5 \\
\hline 1 & 42 & 20 & 0 & 22 & 41 \\
\hline 2 & 41.5 & 21 & 0 & 21.5 & 42 \\
\hline 3 & 40.5 & 20.5 & 0 & 21 & 41.5 \\
\hline
\end{tabular}

After the first bending is finished, all the measuring points are measured for at least a total of 5 times every day.The measured results as a record are put into Table 4. According to the measured data, the elastic rebound value is calculated as: 


$$
\Delta \alpha=\left(\Delta \alpha_{1}+\Delta \alpha_{2}+\Delta \alpha_{3}+\Delta \alpha_{4}+\Delta \alpha_{5}\right)=12.007^{\circ}
$$

At this time,we select the sample 3, and regulates the radius of the different test.The test results is put into Table 5.

Table 5 The rebound value of bending test

\begin{tabular}{cccc}
\hline & & $120^{\circ}$ & $150^{\circ}$ \\
\hline 2 & $90^{\circ}$ & $131^{\circ}$ & $161^{\circ}$ \\
\hline 2.5 & $104^{\circ}$ & $131^{\circ}$ & $161.5^{\circ}$ \\
\hline 5 & $106^{\circ}$ & $132^{\circ}$ & $163^{\circ}$ \\
\hline
\end{tabular}

\section{The experience curve}

Through the statistical analysis of $30^{\circ} 、 60^{\circ} 、 90^{\circ} 、 120^{\circ}$ and $150^{\circ}$ bending test, The test results is put into Table 6 and the experience curve is drawn as in Fig.1.

Table.6 The statistical value and mending of rebound angular

\begin{tabular}{cccccc}
\hline Regular & $30^{\circ}$ & $60^{\circ}$ & $90^{\circ}$ & $120^{\circ}$ & $150^{\circ}$ \\
\hline $3 / S$ & $39^{\circ}$ & $72.5^{\circ}$ & $100^{\circ}$ & $130^{\circ}$ & $160^{\circ}$ \\
\hline 4 & $42^{\circ}$ & $73^{\circ}$ & $102^{\circ}$ & $131^{\circ}$ & $160.5^{\circ}$ \\
\hline 5 & $45^{\circ}$ & $74^{\circ}$ & $103^{\circ}$ & $132^{\circ}$ & $161^{\circ}$ \\
\hline 8 & $47.5^{\circ}$ & $77.5^{\circ}$ & $107^{\circ}$ & $133^{\circ}$ & $163^{\circ}$ \\
\hline
\end{tabular}

$\Delta a$

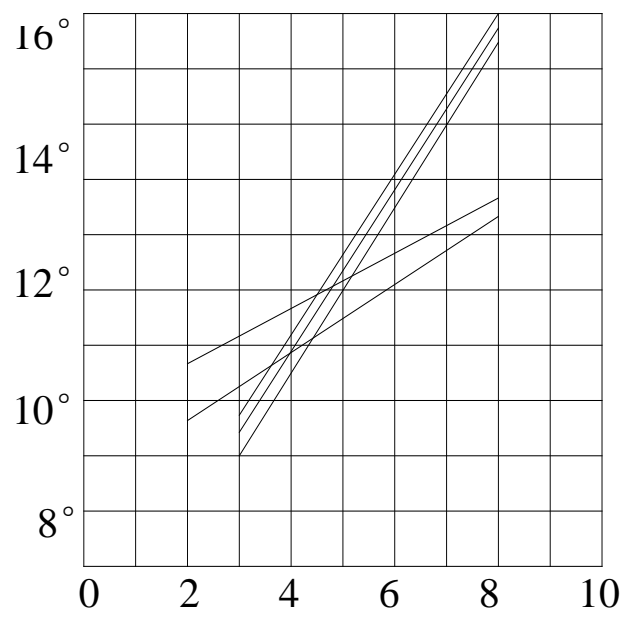

$\mathrm{R} / \mathrm{S}$

Fig1. The curve of rebound angle

\section{Conclusions}

The relative corner radius $\mathrm{R} / \mathrm{t}$ ( $\mathrm{R}$ is for the radius of curvature, $\mathrm{t}$ is for the thickness of the plate) is the larger, the rebound angle is the larger;

The yield point of material is the higher, the rebound angle is the smaller; 
The rebound angle is the bigger, the rebound angle is the smaller;

The elastic modulus is the greater, the rebound angle is the smaller;

When the bend radius is defined,the bend angle is the larger, the rebound angle is the greater.

\section{References}

[1]T.Naka and F.Yoshida.Effect of temperature and forming speed on deep drawability of 5083 aluminium alloy sheet[J].METALS AND MATERIALS.Vol.4,No.3(1998),p.464-466.

[2]F.G.NELSON,J.G.Kaufman.and E.T.Wanderer. Tear Tests of 5083 Plate and of 5183 Welds in 5083 Plate and Extrusions [J] .Advances in Cryogenic Engineering.Vol15,(1995),p.91-101.

[3] Yingwei Hou,Ying Wang. Bending Properties of 5083 Aluminum Alloy [J]. Journal of Dalian Jiaotong,in Chinese.Vol33,No.1(2012),p.65-67.

[4] Lingwu Meng, Gang Sun. Design of no-press-mark bending die for forming process of aluminum alloy plate [J]. China Metalforming Equipment \& Manufacturing Technology, in Chinese. No.3(2014),p.76-78.

[5] Guoqing Yu, Shihong Lu . Study of the Influence Factors on Aluminum Alloy Bending Based on Finite Element Analysis [J]. ,Mechanical Science and Technology.in Chinese,Vol24,No.9(2005) ,p. 1077-1080. 